\title{
MEMORIAL SOBRE A TRAJETÓRIA ESCOLAR BÁSICA DE JOSÉ ELÍADA CUNHA BARBOSA
}

José Elíada Cunha Barbosa ${ }^{1}$

Resumo: O presente texto trata do memorial sobre a trajetória escolar de José Elíada Cunha Barbosa, ex-integrante do Programa Conexões de Saberes. Tem como objetivo apresentar os passos percorridos desde o início da educação básica até a entrada à UFPA e quais os principais entraves de estudantes das comunidades populares adentrarem o ensino superior público. A memória foi usada como principal referência para construção do material. Em seus resultados, apresenta os esforços individual e coletivo para que de fato a educação seja uma questão de direito e não de privilégio de poucos.

"Oh! que saudades que tenho Da aurora da minha da vida,

Da minha infância querida

Que os anos não trazem mais!

Que amor, que sonhos, que flores,

Naquelas tardes fagueiras

À sombra das bananeiras,

Debaixo dos laranjais!"

(Meus oito anos, Casimiro de Abreu)

Em frente à casa, na rua da alameda, estava sentado um menino que tinha por volta de quatro anos de idade. Estava sujo e chorando sem parar. O rosto, de longe, brilhava por causa da quantidade de lágrimas que umedeciam seu semblante. Levava as mãos sujas aos olhos numa tentativa de parar de chorar. Aquela sujeira toda o deixava com uma aparência ainda mais triste. Qualquer um que passasse por ali ficaria com pena do garoto. O rosto brilhoso, grudento e imundo refletia a luz daquela manhã ensolarada, mas ao mesmo tempo, fria. Eram seis da manhã e seus pais ainda dormiam.

Ali, solitário, pensava sobre o mundo, sobre a vida, sobre ele mesmo. Sentia uma tristeza profunda, algo que parecia impossível para um garoto. Podia sentir a maldade do mundo com uma intensidade maior do que as crianças da sua idade.

Felizmente seus dias não eram sempre assim. Havia dias que ele corria por todos os lados da casa procurando uma aventura futurista, ou mesmo, um tesouro enterrado pelos piratas do capitão Alma Negra. Assim passava seu tempo: entre os navegadores de um mar

\footnotetext{
${ }^{1}$ Doutor em Ciências Sociais pela Universidade Federal do Pará, e-mail: barbosa_1011@ yahoo.com.br

Revista PET Interdisciplinar e Programa Conexões /UFPA On-line. Ed. Especial - 2017, BELÉM/ PA - ISSN 2447-097X
} 
localizado no céu e os desenhos animados, em forma de ursos, que desciam no pátio de sua casa em seus carros voadores.

Um pátio e uma imaginação que rompiam as barreiras da realidade cruel. À medida que crescia, sentia mais a animalidade do mundo e isso o atormentava. Os sentimentos novos, as situações que não deviam ter sido experimentadas, o tormento do erro constante o fazia refletir sobre suas dores e naquele dia, prostrado à frente de sua casa, ele precisou sentar para não cair.

Aquele sentimento era novo pela intensidade que apresentava. Era uma raiva que não continha-se no peito. Não sabia ao certo porque chorava, afinal aquelas brigas entre ele e a irmã mais velha eram comuns. As brigas podiam ser as mesmas, mas ele já não o era.

Costumava, em seus momentos solitários, ter pensamentos mórbidos sobre si mesmo, pois não se enquadrava na sociedade mentirosa, manipuladora e desconcertante da qual, mesmo contra sua vontade, fazia parte. Afinal falava a língua dos homens, comia da mesma comida, habitava em um modelo de casa típico da periferia do mundo ocidental.

O garoto não gostava de ver nas pessoas os sentimentos egoístas e mesquinhos da sociedade pós-moderna. Pessoas transbordavam incompreensão e nunca o entendiam e ele por sua vez ficava tentando compreender porque as pessoas tomavam atitudes que para ele eram errôneas. Sempre fora crítico demais para aceitar certas coisas com facilidade.

Num final de semana seus pais o levaram, junto com suas duas irmãs, a um circo que estava fazendo sucesso na cidade. Naquele espaço, embaixo de uma tenda colossal que abrigava um palco de areia tão grande quanto um campo de futebol - pelo menos era isso que aos seus olhos parecia -, havia uma platéia digna de suntuosos e cruéis espetáculos do coliseu romano.

Olhava aqueles animais gigantescos e não achava graça ao vê-los fazer estripulias ao comando dos chicotes do adestrador. Em seguida vinham os palhaços com suas atuações ainda mais repugnantes e cheias de conotações sexuais. Reparara que um palhaço fizera um gesto obsceno em um outro que estava ali parado, o que fez a platéia cair em gargalhada, mas ao contrário dos demais, ele achava aquela cena imprópria para crianças. Tinha apenas seis anos e já conseguia ver mais do que era permitido aos outros de sua idade, mas porque motivo isso acontecia? Essa pergunta ele não sabia responder e na adolescência a resposta também não chegaria.

As constantes mudanças de humor tornaram-se ainda mais presentes quando completara doze anos e junto dela os desejos mórbidos também aumentaram. Em sua cabeça 
confusa, sabia que uma maçã traçara seu destino. $\mathrm{O}$ erro tornou-se o fator dominante nas relações humanas, pois o pecado sucumbiu junto ao mundo que o aceitou em um abraço leal. O pecado original é sem dúvida o retrato de uma história, para muitos, apenas alegórica, que trata de como as relações humanas se desenvolveram no mundo. Chegara à pergunta que muitos se fizeram ao longo da história humana: Porque existo?

Lembrara-se da história que, de vez em quando, sua mãe contava sobre seu complicado parto. A dificuldade de respirar, de estar no mundo, de aceitar a claridade que outrora era vedada pelas vísceras da mulher que o carregava dentro de si, retratam um pouco da luta para enfrentar a morte e permanecer no mundo. Talvez se soubesse que em 1984 o mundo já tinha sido atropelado por duas guerras mundiais, peste bubônica, gripe espanhola, assassinato de Jesus Cristo, ele mudaria de idéia com relação a permanecer em um planeta degradado pelos desejos efêmeros e infestado sem indulgência alguma pelas pragas.

Mas como saberia disso se supostamente viria ao mundo como uma tábula rasa. Mas como saberia de fatos históricos no ano do seu nascimento? Que escolha teria ele se não o de ser empurrado útero a fora pelas leis físicas da vida? Aliás, empurrado não é bem a palavra correta para descrever o seu nascimento: ele foi expulso sem muitas dores do corpo que o transportava.

Na cama de uma maternidade lá estava ela, e ele junto a ela, dentro dela. Era sua cópia genética e nem sabia disso. Ela levantou-se da cama e ele aparecera de repente ao escorregar do seu útero direto para suas pernas, ficando imprensado entre elas. A morte em forma de queda aguardava-o no chão clinicamente limpo da maternidade. Ele poderia ter sobrevivido sem seqüelas se as pernas de sua genitora não fossem fortes suficientes para imprensá-lo? Ou não teria ele sobrevivido à queda?

Um mundo confuso e atormentado o esperava fora daquela maternidade. Logo, ele faria parte dos medos e anseios de uma população que morava no meio de uma floresta tropical.

Uma gestação dificultada pelas crises asmáticas e falta de resistência da mãe fizeram parte da história intra-uterina do garoto. $\mathrm{O}$ parto incomum revelava um bebê com medidas abaixo do considerado normal. No entanto, à medida que o tempo deixava sua marca, as cicatrizes de uma gestação problemática foram sarando sem deixar vestígios. Em pouco tempo a adaptação ao mundo natural foi se tornando menos complicada e mais aceitável.

Revista PET Interdisciplinar e Programa Conexões /UFPA On-line. Ed. Especial - 2017, BELÉM/ PA - ISSN 2447-097X 


\section{Família: um destino cruzado}

Oriundo do Maranhão, o pai do garoto, saiu cedo de sua terra em direção a abundante Amazônia. Maranhão, Pará, Belém, Terra-firme foi o seu roteiro de viagem e este último acabou por tornar-se o seu bairro. Infância marcada pelo abandono do pai, morte prematura da mãe e cuidados da avó materna em uma terra pobre e sem perspectivas de um futuro promissor o trouxeram à Belém, para casa de parentes que tinham a mesma origem.

A trajetória da mãe do garoto também não fora diferente. Saiu do interior do Pará, ilha de Quatipuru, em direção ao urbano, em direção ao sonho de prosperar, em busca de uma história na cidade de Belém. Parou na Terra-Firme e lá os destinos dos pais do garoto se cruzaram.

Juventude do pai e idade avançada da mãe tornou-se um problema para uma sociedade vil e hipócrita que valoriza o corpo e esquece-se da alma. No entanto, um dia todos os caluniadores e amaldiçoadores pagarão o preço da discórdia.

Além de enfrentarem a juventude, a idade avançada, a sociedade mentirosa e difamadora, ainda tinha os problemas financeiros. A mãe do garoto teve de fazer um curso técnico de enfermagem, após passar a sua infância e adolescência trabalhando como doméstica na casa dos urbanos. Teve que correr atrás do tempo perdido. Apenas com o primeiro grau, teve de lutar pelo seu sustento. Vendia produtos de beleza da Avon e da Natura, para conseguir algum dinheiro para sustentar os três filhos.

O pai não terminou nem a $4^{\mathrm{a}}$ série do fundamental. Aprendeu a ler com dificuldades, participou de seminários e cultos evangélicos. Tentou ser pastor e nessa busca a leitura foi sua companhia. A bíblia foi seu incentivo.

Quando chegava o dia das crianças não havia presentes, apenas no natal. Não comemoravam aniversários, pois era gasto de dinheiro. Cresceram assim, sem apegos materiais e sem cultuar tradições dispendiosas. O garoto agradece hoje por isso.

\section{Mas e Terra-Firme?}

Terra-Firme, terra sem lei.

Terra esta marcada pela falta de compreensão da situação humana, da pobreza, da miséria intelectual e da bestialidade dos homens. Quantas situações acabaram em morte na rua onde o garoto reside! Incontáveis vezes se ouvia: "Lembras daquele pequeno? Morreu ontem em uma briga”. Mais um número, mais um dentre os vários que irão passar nas mãos dos funcionários do IML. Apenas um número? Porque nos tornamos simples matemática? 
O garoto nunca esquecera o ar sombrio que recaiu sobre a alameda em que ele morava, num dia qualquer. Era manhã quando souberam que um vizinho havia sido brutalmente assassinado em sua própria casa. Um amigo da vítima bateu a sua porta e o encontrou estirado no chão, com evidentes sinais de briga pela casa. O assassino tentou separar a cabeça do corpo, mas sem sucesso, pois a vítima era um homem de meia idade com os ossos da coluna bem endurecidos.

O corpo estava lá, sendo exibido aos curiosos. É tão estranho perceber uma pessoa depois que ela morre. A consciência incomoda a si própria e se pergunta: "eu via este senhor, mas porque nunca falei com ele?". Aí a consciência começa a lhe culpar.

Nas duas semanas que se seguiram, ninguém sabia quem era o assassino, ou a assassina. Enfim, aconteceu o enterro e os familiares e amigos estavam presentes no funeral.

Analisemos a situação deste senhor: tinha filhos que não moravam com ele, sua mulher também o abandonara, morava numa casa pequena, sozinho, sem companhia alguma, a não ser a dos cigarros que consumia e das bebidas alcoólicas que o perseguiam. Qualquer dinheiro que aparecia através dos "bicos" que fazia, ele investia na bebida. Na noite de sua brutal morte ele saiu com um amigo para beber. Após isso, apareceu morto em sua casa.

Um romance policial de Agatha Christie estava posto sobre a alameda, sobre a terrafirme, dentre os vários que aconteciam todos os dias, mas como todos os contos policiais, a alameda conheceu o assassino.

Um vigia havia visto que a vítima entrara na rua com alguém na noite do seu assassinato. Era um rapaz por volta dos seus 25 anos, vizinho do falecido e amigo, o mesmo que encontrara o corpo e que foi ao funeral da vítima. Após isso, a polícia descobriu que o amigo que havia estado com a vítima o tempo todo, havia se drogado e cometido o assassinato. $\mathrm{O}$ assassino descobriu o corpo e ainda fora ao funeral do amigo.

Trágico? Isso é a realidade e não esqueça: também é a sua!

A vida escolar

O garoto estudara em uma escola estadual perto da sua casa, na qual fizera todo o seu primeiro grau. Da $2^{\mathrm{a}}$ série até a $8^{\mathrm{a}}$. Quando ele passava de uma série a outra era alegria na certa. Porém, um ano estudando após o outro, inevitavelmente, chega um momento que o sistema escolar te cansa. O garoto já não ficava mais admirado ao perceber o fato de que a maior parte dos alunos ia para a escola apenas para poder passar o tempo. Ora, ali estavam os amigos, as namoradas, a farra, a brincadeira...teria lugar melhor para ficar do que a escola?

Revista PET Interdisciplinar e Programa Conexões /UFPA On-line. Ed. Especial - 2017, BELÉM/ PA - ISSN 2447-097X 
O estudo era o que menos importava. Os professores sempre chatos e sem ânimo. A realidade da escola pública vitimiza os seus alunos e os torna seres humanos menores do que quando entraram. Ele ficara ali até a oitava série e pouco se lembrara dos conteúdos das matérias. Apenas estudava para as provas. Não tinha incentivo de levar aquilo para a vida. Era para aquele momento e pronto, usava a fórmula e esquecia-se dela em alguma gaveta da sua mente.

Ele tentara estudar, no segundo grau, em um colégio conceituado, o Paes de Carvalho. Fez até prova de seleção para tentar entrar ali. Isso foi um crime. Processo seletivo para entrar em uma escola pública de segundo grau. Assim também acontece nas universidades públicas desse país, mas a este tipo de seleção, parece que acostumamos e já não achamos um ultraje, pelo contrário, parece que concordamos com esse sistema cruel que privilegia os mais aptos (com mais posses, leia-se aqui) em detrimento da classe popular.

Infelizmente o garoto não conseguira passar no Paes de Carvalho. Aquilo pra ele fora uma derrota. Estava sem rumo, sem escola. $\mathrm{O}$ jeito era continuar na escola que estudava até a oitava série, ali no seu bairro: "Escola Brigadeiro Fontenelle". O garoto nunca esquecera o nome da diretora, pois todos os trabalhos que escrevia tinha que colocar o nome dela. Sebastiana Machado. Ela está lá até dos dias de hoje.

No entanto, parece que havia algo de melhor reservado a vida escolar do menino. O seu pai conseguira uma bolsa em uma escola particular tradicional da cidade. Estudou apenas dois anos ali, o primeiro ano e o terceiro. O colégio chamava-se José de Anchieta. O garoto voltava andando pra casa no sol de meio-dia para economizar a passagem do ônibus para consegui juntar algum dinheiro. Na maioria das vezes não tinha dinheiro para o lanche, logo precisava economizar.

Ali o garoto percebeu que os alunos são tratados de forma diferenciada na rede pública e na rede particular de ensino. Uns com mais direitos de vencer do que outros. Ali o que não faltava era incentivo para que os alunos passassem no vestibular.

Mesmo em um colégio particular, o garoto nunca negara suas origens. Sempre dizia que morava na terra-firme. Era um comentário geral. "Terra-firme, perigoso né?". Apesar dos dois anos que passara ali ele conseguira entender a importância da educação, o que nos oitos anos de escola pública o garoto não tinha conseguido. Apesar disso, esses dois anos em escola particular não iriam sanar os oitos anos de ensino defasado do fundamental.

Tentou seu primeiro vestibular para ciência da computação. Acreditava que iria passar. Um dia antes da prova do vestibular, lendo um dos livros da escola, teve um aviso. Na cabeça

Revista PET Interdisciplinar e Programa Conexões /UFPA On-line. Ed. Especial - 2017, BELÉM/ PA - ISSN 2447-097X 
dele sabia que devia gravar um pequeno texto que acabara de ler. O texto versava sobre leitura, o tema da redação do vestibular do dia seguinte. Deus o avisara e dera um presente a ele, não duvidava disso. Fizera a prova e passara para segunda fase, mas não conseguiu passar em física. Perdeu um ano. Junto a isso vieram às cobranças e a falta de otimismo pela parte do pai. Este chegara a dizer que o filho não passaria novamente no vestibular, em uma das constantes discussões que travavam.

No segundo ano, estudara em um cursinho popular. Sabia ele que se tentasse ciência da computação novamente, ele estaria mais um ano em uma sala de aula, revendo aquelas matérias chatas e professores que adoravam contar piadas sexualizadas em vez de dar aula.

Não podia passar humilhações de novo dentro de casa, logo decidiu escolher um curso que tinha chances de passar. Escolheu Ciências Sociais para que não tivesse que sobrecarregar os pais e a si próprio novamente. Precisava passar dessa vez.

O garoto estudava a noite no cursinho popular e a tarde toda tentava estudar as matérias para o vestibular.

Chegara o dia do vestibular. Ao sair da sala, a qual estivera fazendo prova, sentia que tinha se saído bem e de alguma forma sabia que iria passar. Foi um acontecimento histórico ao ouvir seu nome no rádio, meses depois da prova. Naquele dia se quebrou um ciclo de exclusão social por meio da educação superior.

O primeiro da família a cursar uma universidade. O primeiro.

Era irreal, era surreal...era real.

O primeiro de uma descendência de miséria e poucas oportunidades chegou à universidade. Espaço de interação, de superação, de conquistas e de batalhas. A universidade ainda carrega a lógica perversa da subordinação e da instucionalidade. Mas isso é só mais uma etapa dentre as muitas que o garoto levou para chegar a educação superior. Não é nada demais, venceu etapas muito difíceis anteriormente, irá vencer esta. Aliás, já venceu. Esta prestes a se formar e já está no mestrado. Esse é só mais um passo para conseguir o tão sonhado lugar ao sol.

"Tu, porém, tens seguido, de perto, o meu ensino, procedimento, propósito, fé, longanimidade, amor, perseverança. As minhas perseguições e os meus sofrimentos, os quais me aconteceram em Antioquia, Icônio e Listra, - que variadas perseguições tenho suportado! De todas, entretanto, me livrou o senhor. Ora, todos quantos querem viver piedosamente em Cristo Jesus serão 
perseguidos. Mas os homens perversos e impostores irão de mal a pior, enganando e sendo enganados.

Tu, porém, permanece naquilo que aprendeste e que foste inteirado, sabendo de quem o aprendestes. E que, desde a infância, sabes as sagradas letras, que podem tornar-te sábio para a salvação pela fé em Cristo Jesus.

Toda a Escritura é inspirada por Deus e útil para o ensino, para a repreensão, para a correção e educação na justiça, a fim de que o homem de Deus seja perfeito e perfeitamente habilitado para toda boa obra." (2 Tm, cap 3 vers 10-17)

\section{Agradecimentos}

Quero agradecer primeiramente ao meu Deus que sempre esteve comigo e nunca me abandonou. Te agradeço Senhor.

Agradecer aos meus familiares pelo apoio e por suportar as brigas e saber perdoar nos momentos oportunos. Deus abençoe a todos nós.

Quero agradecer a todos os meus amigos e amigas do curso de Ciências Sociais: Grande amiga Joyce, Larissa, Liliane, Elayne, Bárbara e Clélio.

As minhas orientadoras: Graça Ferraz e Maria Dolores. Meus sinceros agradecimentos. Graça obrigado por tudo! Devo muito a você por acreditar em mim.

Ao meu amigo Samyr (UFPB) e ao meu amigo Demócrito (UFPE)

A todos os amigos e amigas do Conexões de Saberes, programa que mudou minha perspectiva de vida: Neide, Deylane, Dayse, Charlene, André, Joel, Carlas, Mauricirlene, Yasmin (UFAC), Helder (UFAM), Francini (UNIR), Laury (UNIR), Lídia(UNIR), Juliana (UNIR), Francisco Marcelo (OF), Alessandra, Adelaides, Andreza,Jaira, Jéssica, Maricélia, Núbia, Poliana, Raimunda, Rosileia, Samara, Shirlene, Maria José, Telma e Ney Cristina. 